\title{
Desenho de Som - Bom Retiro 136 Quilômetros
}

Para mim o processo de 'Bom Retiro 958 Metros' significa uma formação muito intensa; tive o grande privilégio de participar deste projeto desde a idéia inicial, até a realização da temporada do espetáculo, coisa que nunca havia feito em um trabalho dessa dimensão. Tive de "inventar" para mim mesmo uma maneira de trabalhar o som no processo do Teatro da Vertigem (coisa que venho fazendo desde que trabalho com o grupo) e tive de descobrir - enquanto fazia - de que maneira a criação sonora se encaixa na pesquisa do Vertigem e em quais momentos; para isso sempre achei, do alto de minha inexperiência, que participar o máximo possível das etapas do trabalho seria a melhor coisa a fazer.

A base da pesquisa sonora do espetáculo se formou na fase de workshops; meu entendimento do trabalho de workshops foi de que ele tem a função de gerar matéria-prima cênica, dramatúrgica, plástica e sonora; então TUDO o que apareceu em termos de som nos workshops eu organizei em um banco de sons enorme que foi o solo a partir de onde trabalhamos na fase seguinte. Passei três meses sem ouvir nada deste material dos workshops e comecei os ensaios como se este banco de sons fosse novo.

A trilha sonora do espetáculo foi uma co-criação, na verdade pode-se dizer isso de toda a concepção sonora de 'Bom Retiro 958 metros'; Erico Theobaldo assina a trilha junto comigo e passamos a dar corpo ao conceito da trilha durante a fase de ensaios, ainda na sede do Vertigem. Foi um trabalho de "polir" o banco de sons que já existia dos workshops, jogar coisas fora, trabalhar coisas, mixar e remixar outras e, principalmente, conciliar as minhas referências e visões com as dele; de certa maneira ele trazia um olhar "de fora" entrando nesta fase que já tínhamos uma primeira versão do texto, não

\footnotetext{
${ }^{1}$ Miguel Caldas é músico, sonoplasta, um dos autores da pesquisa musical e o responsável pela execução da trilha e pelo som móvel do espetáculo Bom Retiro, 958 metros.
} 
havia participado dos workshops, então trazia outras referências e não tinha nenhum apego pelo que foi levantado anteriormente, o que fez com que fosse mais fácil eliminar coisas fracas e desenvolver a sonoridade de uma maneira mais "fresca"; ainda tendo a pesquisa como base, mas se utilizando dela de maneiras mais práticas.

Se considerarmos workshops e ensaios foram 12 meses onde surgiram referências de: objetos que falam, musicais, rezas hebraicas, fantasmas, música acusmática e ruídos, música armênia, robôs, sinfonias, sons espectrais, música grega, pop grego, pop coreano, Klezmer, trilhas de super-heróis, cantigas judaicas, pop judaico, cumbia, ópera, música folclórica boliviana, música religiosa coreana, extensas gravações de trens, portas automáticas e máquinas de costura, música de desfile de moda, rádios piratas, karaokê, aparelhagem paraense, todo tipo de mp3 vagabundo, mais máquinas de costura, criações de sons de sintetizador e mais o que possivelmente me esqueci. O que ficou claro para nós quando terminamos a fase dos ensaios, antes de irmos trabalhar in-loco no Bom Retiro, é que, de alguma maneira, queríamos extrair a SONORIDADE de algumas dessas referências e utilizar estas sonoridades (timbres, batidas, equalizações, etc.) para compor a trilha do espetáculo, mas não usar as referências tão puramente; em outras palavras sentíamos a necessidade de sintetizar musicalmente o Bom Retiro que estava sendo discutido pelo Vertigem.

Mas o ponto crucial da pesquisa de som de ‘BR958m' foi o sistema de som móvel. Para falar de como o som móvel surgiu no espetáculo, preciso voltar brevemente para a intervenção cênica Mauísmo, que foi dirigida pelo Guilherme Bonfanti e pela Eliana Monteiro em 2010. Na segunda vez que fizemos o Mauísmo pelas ruas do Bexiga, um dos vários desafios que apareceram no desenvolvimento da sonoplastia para a intervenção foi criar um som móvel (sem cabos) com potência suficiente para preencher sonoramente a rua e autonomia suficiente para durar toda a intervenção; liguei para o Kako Guirado e ele me deu algumas luzes de como fazer. Montei um sistema que o Roberto Audio empurrava pela rua e funcionou perfeitamente. Esse sistema ficou "na gaveta" até eu ver, nos workshops do Bom Retiro, a necessidade de um som móvel para a rua e o shopping.

A sonorização dos workshops do Bom Retiro foi, por pura necessidade e conveniência, feita com um amplificador velho amarrado num carrinho de carga (as vezes até amarrado na capota do carro e eu dirigia pelo bairro operando a trilha com o notebook no banco do passageiro); isto se tornou uma característica do processo 
e o principal conceito da sonoplastia: o som que acompanha a cena, transita pelos espaços e os infiltra, "leva" de uma cena para outra e é uma mistura do que é 'hi-tech' com o que é gambiarra e é 'low-tech' (amplificador e notebook amarrados com cordas num carrinho de carga velho e detonado). Durante 3 meses de workshops e 9 meses de ensaios arrastei o velho 'Antera' pelo Bom Retiro e ele se tornou a peça principal do som do espetáculo, até o Kako Guirado integrar o processo e então começamos a expandir esta idéia do carrinho de som.

O que fazer? Uma Kombi de som? Um ônibus? Um carrinho de golfe? As duas primeiras idéias logo se mostraram inviáveis e foram descartadas, eu e Kako ficamos com carrinho de golfe como a melhor, mas esta também caiu depois de pouco tempo; visualmente e cenicamente não teria nada a ver com o conceito do espetáculo; estávamos pensando não só um sistema de som, mas uma espécie de "alegoria" que iria acompanhar o espetáculo, dizia respeito a todas as áreas de criação. Um dos objetos que foi muito discutido e utilizado durante todo o processo é o carrinho de catador de material reciclável, então decidimos criar este som móvel neste sentido; um carrinho de catador que não está carregando entulho, e sim carregando o sistema de som da peça, mantendo a idéia do 'hi-tech' misturado ao 'low-tech' e puxado por uma pessoa, o que dialoga com o conceito do homem-objeto ou objeto-humanizado que foi muito explorado no processo.

Eu havia me comprometido não só com a criação da trilha, mas também com a operação do som do espetáculo (como disse, quis participar do processo completo) percebi então que isso significava que eu havia me comprometido em puxar sozinho este carrinho de som com duzentos quilos de equipamentos; iria precisar pensar com muito cuidado neste carrinho e - com suficiente medo e preocupação - comecei a desenhar um carrinho de catador que pudesse ser puxado sem o uso das mãos para que eu as tivesse livres para operar o som; sentei com meu velho pai Renato Caldas que é arquiteto e foi cenotécnico durante muitos anos e ele me disse "vamos pensar numa charrete puxada por um homem", isso ainda dialogava com mais um aspecto da criação da peça: o homem-animal ou animalizado.

Após três versões construídas pelo exímio Gerson "Gereba" Rodrigues e sua equipe, chegamos à definitiva; que deixa as mãos livres para operar, é puxado por apenas um homem, tem boa mobilidade e aguenta todos os equipamentos necessários. 


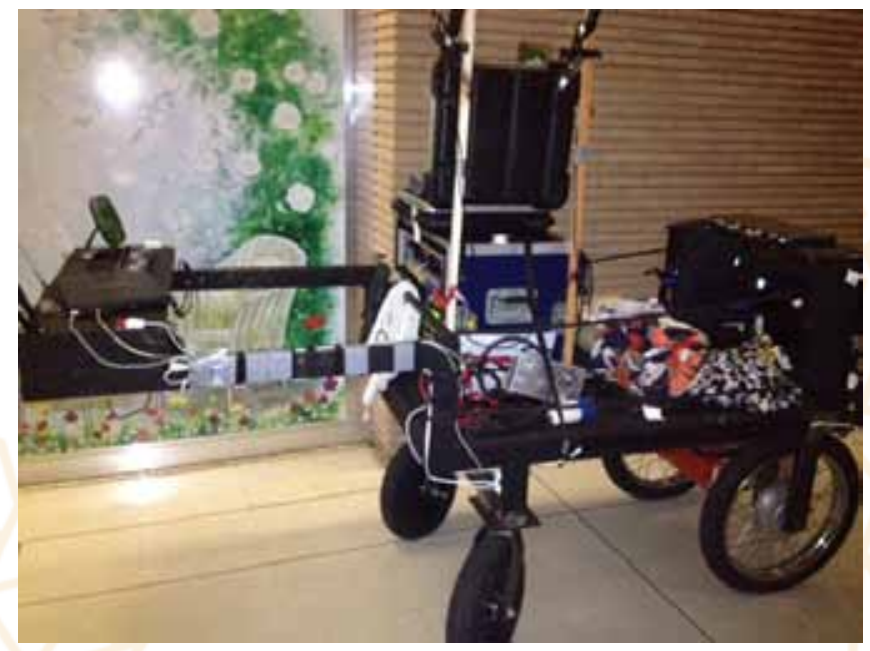

Foto do carro definitivo, por Miguel Caldas

O conceito do som móvel ainda se expande além deste carrinho, desde o início queríamos um som que estivesse infiltrado nos espaços, pesquisamos caixas de som independentes de diversos tamanhos mas o problema era controlá-las, queríamos centralizar a operação do som por mais que quiséssemos, ao mesmo tempo, 'espaIhar' o som; o Kako deu a saída para esta sonorização móvel completa e adaptável com caixas de som totalmente independentes de cabos que podem ser carregadas como malas e ainda assim a operação toda fica centralizada no carrinho. O sistema é totalmente operado (carrinho, caixas móveis e microfones) por três pessoas, isso foi resultado de uma coordenação logística muito precisa da movimentação das caixas e do carrinho e também do desenvolvimento de algo que há tempos o Kako sentia vontade de fazer: eliminar a mesa de som e centralizar a operação de trilha sonora e microfones em um único software em um único computador; tivemos as inestimáveis ajudas de Amilcar "Mica" Farina na maneira de organizar o software e de Fernando Narcizo na equalização dificílima das vozes nos espaços. Já fizemos 71 espetáculos desde a estréia em 14/6 e rodei, sem contar nos ensaios, 136 quilômetros puxando o carrinho de som.

Acredito totalmente que em uma criação sonora, qualquer que seja, o 'quê' é indivisível do 'como'; a maneira com a qual você desenha e propaga o som se torna conteúdo da própria trilha; isso é um aspecto fundamental da criação sonora dentro da pesquisa do grupo; a pesquisa de sonorização dos lugares aonde os trabalhos são realizados é o que determina a "dramaturgia" do som no Vertigem. 